\title{
Exploring the role of content knowledge in responsive teaching
}

\author{
Amy D. Robertson and Lisa M. Goodhew \\ Seattle Pacific University, Department of Physics, \\ 3307 Third Avenue W, Suite 307, Seattle, WA, 98199-1997
}

\begin{abstract}
In this paper, we begin to explore the role of content knowledge in responsive teaching (RT), using in situ data to draw out and speak to a latent disagreement within the RT literature. We claim that one role that content knowledge plays in RT is to support teachers in eliciting, seeing, and then pursuing disciplinary connections within their students' thinking. We suggest implications for teacher preparation.
\end{abstract}

\section{INTRODUCTION}

Recent STEM education reforms (e.g., [1]) emphasize student engagement in scientific practices, alongside and integrated with their learning of core content. Concurrent (and consistent) with this emphasis are re-imaginings of the core practices of ambitious, equitable STEM teaching [2], including the centrality of attending and responding to students' thinking. Together, these visions call for science classroom practice that is centered on the pursuit and refinement of students' intuitive sense-making about the physical world. Responsive teaching (RT) - or teaching that (1) foregrounds the substance of students' ideas, (2) recognizes disciplinary connections within students' ideas, and (3) takes up and pursues the substance of students' ideas $[3,4]$ - is one instructional approach that exemplifies these visions, and it embeds the assumption that students come to the classroom with "wonderful ideas" [5] that can serve as the foundation for the class' learning. In responsive classrooms, the curriculum emerges from these ideas and from students' generative engagement and questions.

A number of professional development efforts across the STEM disciplines have been designed to support teachers in learning to enact RT practices. Within the literature depicting this professional development, there are different takes on the skills, dispositions, and/or knowledge that teachers need to be able to attend and respond to their students' thinking. For example, several authors suggest that teachers need practice in listening and responding to students' thinking (e.g., [6,7]). Others emphasize the importance of particular skills in noticing certain aspects of student thinking (e.g., [8,9]). Still others argue for the importance of a commitment to listening to and working to understand the substance of students' ideas (e.g., [10,11]), and still others discuss the importance of framing activities as opportunities for sense-making, rather than as answerseeking (e.g., $[12,13])$.

Within the RT literature, there is very little mention of the need for or role of teacher content knowledge, and even among the subtle nods toward the importance of this kind of knowledge, there is disagreement. For example, Wallach and Even [14] suggest that one teacher's content knowledge may contribute to her over-filtering her students' mathematical thinking. On the other hand, quotes from practitioner accounts of RT (e.g., [15,16]) suggest the importance of content knowledge for understanding the disciplinary significance of students' ideas. For example, Ball says, "To do this [RT] productively, I must understand the specific mathematical content and its uses, bases, and history, as well as be actively ready to learn more about it through the eyes and the experiences of my students."

In this paper, we begin to explore the role of content knowledge in RT, aiming to initiate a data-driven conversation that can speak to this latent disagreement in the literature. We briefly consider how our work could influence the preparation of responsive teachers, and how this preparation might be informed by both existing RT professional development and the wisdom of the physics education research community, which has focused extensively on the development of teachers' conceptual understanding in physics (e.g., $[17,18])$.

\section{RESEARCH METHODS}

To explore the role of content knowledge in RT, we looked for cases of [19] RT in the context of K-12 lessons about energy, since this content area is the focus of our research team's project-wide efforts. Our criteria for calling an episode "responsive" was that it loosely satisfied the three characteristics of RT we articulate in the Introduction.

For this exploratory work, we selected an episode from Mark' ${ }^{1}$ eighth grade physical science class at an integrated suburban middle school in the Pacific Northwest. (We describe the episode in more detail in Section III.) We analyzed the episode turn by turn [20], breaking it into smaller episodes that corresponded to the teacher's responsive talk moves. For each smaller episode, we (1) characterized the teacher move, drawing from literature on responsive discourse moves [21-24], (2) identified evidence of content knowledge in use by the teacher (if any), and (3) examined ways in which the responsive move relied on the content knowledge. This process was emergent and grounded in the episodes themselves; we did not look for instances that exemplified particular responsive moves, beyond generally satisfying the overarching characteristics

\footnotetext{
${ }^{1}$ All names in this paper are pseudonyms.
} 
described above, nor did we seek out particular forms of content knowledge on display. Our final analysis was coconstructed by both authors, enhancing the interpretive and theoretical validity of the account [25].

This small sample size and case study analysis is appropriate for the purposes of exploring the role of content knowledge in $\mathrm{RT}^{2}$ Our point is not to make a representative claim or to speak to the general need for particular facets of teacher knowledge about energy; it is to use in situ data to draw out and speak to a latent disagreement within the literature. We are continuing to flesh this work out with additional cases in an in-progress manuscript.

\section{RESEARCH CONTEXT}

Prior to the start of the episode, Mark's eighth-grade physical science students watched a movie that illustrates various everyday scenarios - a bus moving down the street, a bicycle being pedaled by a person, leaves blowing in the street, etc. - and then broke into small table groups to discuss whether or not these scenarios "involve energy."

The episode begins when, in the midst of their small group discussion, one group of five students - Ashley, Brianna, Christopher, Danielle, and Emily - calls Mark over to share their debate about whether there is energy involved in leaves blowing in the street. Central to their debate is whether moving leaves have energy, or whether they just use energy from the wind. They seem to think the latter, but they hesitate because they can think of other ways in which the leaves might have energy, such as their being alive or their being able to burn. The students alternate between playful frustration with one another and discussion and debate. After several minutes, Mark introduces a new scenario - a ball rolling on the ground and asks whether the ball would have energy. Christopher points out that someone would have to give the ball a push to get it rolling, which prompts Mark to change his scenario to a ball rolling down a hill, with no one pushing it. Would that have energy? Mark discusses this new scenario with the students for a short time and then he leaves the table without the students having come to a consensus. A full transcript of the discussion can be viewed at the following link: goo.gl/upyK $4 z$.

\section{MARK ORGANIZES STUDENTS' IDEAS AND REVOICES THEM IN DISCIPLINARY TERMS}

Organizing students' ideas and revoicing them in disciplinary terms requires the instructor to understand the

\footnotetext{
${ }^{2}$ This is especially true given the dynamic nature of RT, where teachers respond to the ideas that emerge from students and adapt their curriculum on the basis of these ideas. Questions about what informs this kind of instruction is best understood in the context of an unfolding interaction between teachers and students.
}

substance of students' ideas in order to select and sequence his or her revoicing of them. This move encompasses other responsive moves discussed in the literature, including O'Connor and Michaels' "revoicing" [21], Pierson's "uptake" ("students' ideas taken up through revoicing, expanding, clarifying, giving an ex[ample] or illustration") [22], Lau's "building on student ideas" in ways that preserve the student's original point or "interpreting student ideas" [23], and Levin's "rephrasing the idea" [24]. We give two examples in which Mark organizes his students' ideas around particular disciplinary facets of energy.

\section{A. Mark revoices the idea that "doing things" requires a source of energy.}

Near the beginning of their discussion, Mark's students bring up the idea that leaves in the street move because of the wind, which is like a source of energy. Mark draws out a connection between these ideas and earlier ideas about energy sources for a bus or bicycle:

8. Brianna: Cause we feel like, okay, a leaf has energy. It's a living thing, living things have energy. But are we talking about energy, like, in the fact that it moves? (And then, like, well) it needs wind to move it. The leaves in the street are just lying there basically. You can say it does because you need wind to move it? Wind it what, it doesn't.

9. (Danielle says something inaudible about the wind.)

10. Emily: Like, it has a source of energy.

11. Brianna: Yeah, it has a source of energy, but I mean, and it's, I guess you can say it's involved in energy because you can burn it and it emits flames, but I mean it's like, not, you know, in motion.

12. Mark: So it sounds like you guys are saying, it sounds like you guys are saying a number of things. So first off, going back to the bus and the bike, you said that they have kind of a source of energy.

13. (Students agree.)

14. Mark: And so since they have a source of energy, they were doing something? Is that?

In his response to Brianna in lines 12 and 14, Mark organizes several things the students have said (e.g., leaves need a source of energy to move; buses and bicycles have sources of energy in gasoline and people), around a generalizable disciplinary concept that connects their ideas: "doing things" requires energy. He does more than restate Brianna's and Emily's ideas, he connects them causally: the source makes the action possible. In making this generalization, we infer that Mark uses content knowledge that motion requires energy, and that energy must come from somewhere (i.e., energy is conserved). This content knowledge helps him interpret the students' implicit questions as being about motion requiring energy, and it helps him see how the ideas they share about sources of energy are related to their question. 


\section{B. Mark revoices the idea that perceptible indicators evidence the presence of energy.}

Leading up to the following snippet, Mark's students are discussing whether leaves sitting in the street have energy, as compared to leaves moving in the street. Emily brings up an alternative way in which the leaves might have energy they are alive - which initiates a disagreement between Brianna and Christopher:

25. Emily: Well, wait, with the leaves on the ground, though, technically, are they still alive?

26. Brianna: Yeah, they are still alive but they're not moving.

27. Emily: Are they still, like, growing?

28. Brianna: No, they're not growing.

29. Christopher: (They don't have energy, they're dying.)

30. Brianna: Leaves on the ground don't grow. They're dying.

31. Danielle: (inaudible) they're off the tree.

32. Christopher: So they do not have energy.

33. Brianna: But they do have energy because you can still use leaves on the ground to burn something.

34. Danielle: You can burn anything.

35. Christopher: Uh, no but if you're (inaudible).

36. Mark: So that's an indicator to you, evidence for you is that if something is, if we can burn something, that means it must have had energy.

In line 36, Mark revoices what Brianna says, but instead of repeating her words he adds to them, to highlight burning as "an indicator" or "evidence" of energy. Because Mark uses such terminology, we infer he is drawing on knowledge that burning is evidence of energy. Mark's statement is also more general than what Brianna said: it is not just that leaves have energy if they can burn; it is that things that can burn have energy. Because Mark generalizes Brianna's idea and foregrounds the concept of indicators or evidence of energy in his restatement, we infer that Mark uses knowledge that perceptible indicators evidence the presence of energy. This content knowledge would allow him to see that burning is a particular kind of evidence and pick this idea out as a productive direction to highlight.

\section{MARK CHOOSES AN EXAMPLE THAT TAKES UP AND CLARIFIES STUDENT THINKING}

In choosing an example that clarifies or extends student thinking in ways that preserve its essence, the instructor must attend to students' ideas and notice the connection between these ideas and the discipline. This move is one type of Lau's "building on student ideas" [23], Levin's "shifting the flow of classroom activity in a way that addresses [a student's] idea" [24], and Pierson's "uptake" (defined above) [22].

In the snippet below, Mark chooses an example that isolates the question his students have been grappling with: is it that leaves (and other moving objects) have energy, or is it that they use energy from an obvious source (e.g., wind)?

63. Christopher: Because when you just, like, press the pedal, the whole bus just, like, takes the gas, turns it into, like.

64. Brianna: Well it uses that energy the gas has.

65. Christopher: So it uses your energy to make the bus move.

66. Mark: So are you saying the, the, like the gasoline is the energy?

67. Brianna: Yeah, the gasoline is the energy, and the bus uses the energy to power itself. Like, you know, the leaves use the wind to move. And like we use, you know, whatever we have inside our bodies to function and all that good stuff.

68. Mark: So what if, um, so go to like the, like, the rolling ball. So you see a ball rolling, uh, on the ground. Does that, does that have energy?

69. Christopher: Energy can't (go) on its own. Cause, like, you always, like, need a helper, and then, like, it goes.

70. Mark: So aside from, we know that, like, I gave it a push. But forget that. Like, (inaudible), we don't see anything pushing it. We just see it rolling. Or let's say, let's just say we set a ball on a hill. And it starts rolling down the hill. Does that ball have energy?

In inventing this example, we infer that Mark uses content knowledge that energy is associated with motion: Mark's example of the ball rolling on the ground takes away a visible energy source (e.g., gasoline for the bus), which suggests that he knows that the ball can still have energy even if it does not have a visible "fuel." This content knowledge is further evidenced by the fact that Mark modifies his example to a ball rolling down a hill to remove any implications of a push from someone. What is striking about this knowledge is what it reflects about Mark's understanding of his students' question: by taking away a visible energy source, Mark's proposed example takes up their question of whether a moving object can have energy, or whether it just uses energy (from a source).

\section{DISCUSSION}

Common to all three of the examples above is an effort on Mark's part to make disciplinary connections within and between students' ideas. This suggests that one role that content knowledge can play in responsive teaching is to support teachers in eliciting, seeing, and then pursuing disciplinary connections within their students' thinking.

Although our analysis is limited to three short snippets, Mark instantiates more general responsive moves, and the moves themselves seem to rely on content knowledge. In other words, it is not just that Mark draws on content knowledge when organizing and restating in disciplinary terms; it is also that the move itself seems deeply tied not 
only to a teacher's sense of their students' ideas, but also to knowledge of the discipline. Even more generally, seeing and pursuing disciplinary connections within and across students' ideas seems to necessitate knowledge of the discipline. Which brings us to the following point: our analysis highlights the intellectual rigor of the kind of responsive teaching that authors like Ball [15], Hammer [16], and others describe in practitioner accounts. This teaching is more than "observational listening," or "listening with an attempt to hear the child's thinking...with [only] nascent formulations about what is heard and few active attempts to support or extend that thinking" [26]. It involves thoughtfully and flexibly using multiple forms of knowledge, including content knowledge, to extend and refine the nascent science in what students are saying and doing. It may also be the case that responsive teaching draws on different kinds of content knowledge than more traditional forms of teaching; this question could be the subject of future, more extensive analysis.

Though not the focus of our analysis, there were instances in Mark's extended episode when his responsive moves seemed not to rely on content knowledge but instead to rely on other forms of knowledge, commitments, or dispositions. For example, in line 51, Mark says, "That's good. I like that," in response to Brianna's exclaiming that she's "working it through in [her] mind!," suggesting a commitment to encouraging his students' efforts to try out and make sense of different ideas, or to recognizing productive metacognition at play. In general, many of Mark's other responsive moves throughout the extended episode point to knowledge and commitments other than content knowledge, such as commitments to understanding students' thinking, epistemological understandings about constructing evidence-based arguments, or knowledge of

1. NGSS Lead States, Next Generation Science Standards: For States, By States, Washington, DC: National Academies Press, 2013.

2. J. Thompson, M. Windschitl, and M. Braaten, Am. Ed. Res. J. 50, 574 (2013).

3. A. D. Robertson, et al., in Responsive Teaching in Science and Mathematics, edited by A. D. Robertson, R. E. Scherr, and D. Hammer, New York: Routledge, 2016, pp. 1-35.

4. D. Hammer, F. Goldberg, and S. Fargason, Rev. Sci. Math. ICT Ed. 6, 51 (2012).

5. E. Duckworth, "The having of wonderful ideas" and other essays on teaching and learning, New York: Teachers College Press, 2006.

6. M. Lampert, et al., J. Teach. Ed. 64, 226 (2013).

7. D. L. Ball and F. M. Forzani, J. Teach. Ed. 60, 497 (2009).

8. M. G. Sherin and E. A. van Es, J. Tech. Teach. Ed. 13, 475 (2005).

9. V. R. Jacobs, L. L. C. Lamb, and R. A. Philipp, J. Res. Math. Ed. 41, 169 (2010).

10. D. M. Levin, D. Hammer, and J. E. Coffey, J. Teach. Ed. 60, 142 (2009).

11. J. E. Coffey, et al., J. Res. Sci. Teach. 48, 1109 (2011). what it means to "feel like a scientist" [27]. These findings corroborate the recommendations of the RT literature - RT does entail a commitment to listening, etc., and the moves served by this knowledge are important to the culture and practices of a scientific classroom community.

To be clear, in claiming that content knowledge supports teachers in seeing and pursuing disciplinary connections within and across students' ideas, we are not claiming that Wallach and Even [14] are wrong; certainly content knowledge can over-filter teachers' listening and/or constrain their responsiveness. However, it can also support their responsiveness, in the ways we articulate. In other words, the role of content knowledge in supporting the enactment of RT is more nuanced than "it does" or "it doesn't." Which leads us to our final point: in this era of educational reforms, teachers are expected to be "both responsive to students and responsible to [the discipline]" [15]. In such an era, we suggest that teacher education focus both on development of content knowledge and on intentional practice in attending to, identifying the disciplinary productivity of, and responding to student thinking. Exclusive focus on the former may contribute to the over-filtering that Wallach and Even warn us about, whereas exclusive focus on the latter may promote a view of teaching as "observational listening."

\section{ACKNOWLEDGMENTS}

This material is based upon work supported by the NSF under Grant No. 122732. We gratefully acknowledge the thoughtful feedback offered by S. Vokos, A. R. Daane, L. S. DeWater, K. E. Gray, S. B. McKagan, R. E. Scherr, L. Seeley, A. Elby, M. J. Luna, J. Richards, R. S. Russ, and J. Walkoe.

12. P. Hutchison and D. Hammer, Sci. Ed. 94, 506 (2010).

13. R. Bresser and S. Fargason, Becoming Scientists: InquiryBased Teaching in Diverse Classrooms, Grades 3-5, Portland, ME: Stenhouse, 2013.

14. T. Wallach and R. Even, J. Math. Teach. Ed. 8, 393 (2005).

15. D. L. Ball, Elem. Sch. J. 93, 373 (1993).

16. D. Hammer, Cognition Instruct. 15, 485 (1997).

17. J. R. Thompson, W. M. Christensen, and M. C. Wittmann, Phys. Rev. ST PER 7, 010108 (2011).

18. E. Etkina, Phys. Rev. ST PER 6, 020110 (2010).

19. F. Erickson, in Handbook of Research on Teaching, edited by M. C. Wittrock, New York: Macmillan, 1986, pp. 119-161.

20. B. Jordan and A. Henderson, J. Learn. Sci. 4, 39 (1995).

21. M. C. O'Connor and S. Michaels, Anthropol. Educ. Quart. 24, 318 (1993).

22. J. Pierson, Ph.D. thesis, University of Texas at Austin, 2008.

23. M. Lau, Ph.D. thesis, University of Maryland, 2010.

24. D. M. Levin, Ph.D. thesis, University of Maryland, 2008.

25. J. A. Maxwell, Harvard Ed. Rev. 62, 279 (1992).

26. S. B. Empson and V. R. Jacobs, in Tools and Processes in Mathematics Teacher Education, edited by D. Tirosh and T.

Wood, Netherlands: Sense Publishers, 2008, pp. 257-281.

27. L. Z. Jaber and D. Hammer, Sci. Ed. 100, 189 (2016). 